\title{
reviews
}

THE distinguished biochemist Parnas once invited me to look at his collection of offprints. At first there seemed to be nothing unusual about them; all I saw were the familiar rows of labelled boxes. Then Parnas explained what was unusual : the offprints, from hundreds of authors, were catalogued under the names of only five or six biochemists. "When I read a paper", Parnas said, "I recognise in it the ideas of one or other of no more than six creative men - Hopkins, Englehardt ....-and I classify the paper accordingly".

The Creative Process in Science and Medicine* quotes a remark by Lewis and Randall (from a treatise on thermodynamics) which is similarly perceptive. The edifice of science is like that of a cathedral built by a few architects and numerous workmen. A scientist does not have to be creative in order to be a valuable member of the scientific community. But the grand design of the edifice of science depends on the creative activities of a mere handful of workers.

What is the secret of this rare creative faculty? In May 1974 C. H. Boehringer Sohn organised a symposium to ask this question. Twenty four people assembled at Kronberg for a couple of days to converse about the creative process in science and medicine. This book records their conversations.

Most unscripted discussions on radio and television are vapid and frothy: they rarely rise to a level which makes it worth while to set them in print. This little book demonstrates that unscripted discussions can be illuminating as well as lively. For two reasons, these conversations are well worth printing: first, some of the contributors are in the front rank of creative scientists (they include four Nobel prizewinners); second, the conversations have been edited with great skill, so that they cleverly combine informality with clarity.

Monod opened the discussions by giving his views about what he called "ingredients" of the creative process,

*The Creative Process in Science and Medicine. (Proceedings of the C. H. Boehringer Sohn Symposium, May 1974.) Edited by Hans A. Krebs and Julian H. Shelley. Pp. xii +138 . (Excerpta Medica : Amsterdam; American Elsevier: New York, 1974.) Dfl.52; $\$ 21.75$. illustrated by the steps of reasoning which went into some of his own classical work on enzyme action. The theme was taken up by Krebs, Popper, Eisenberg, Eigen, Eccles, Tinbergen, and others. Occasionally the distinguished party strayed from the theme or followed some wayward idea like kittens playing with a ball of wool; but in the end a remarkable consensus

\section{Playing with ideas}

$$
\text { Eric Ashby }
$$

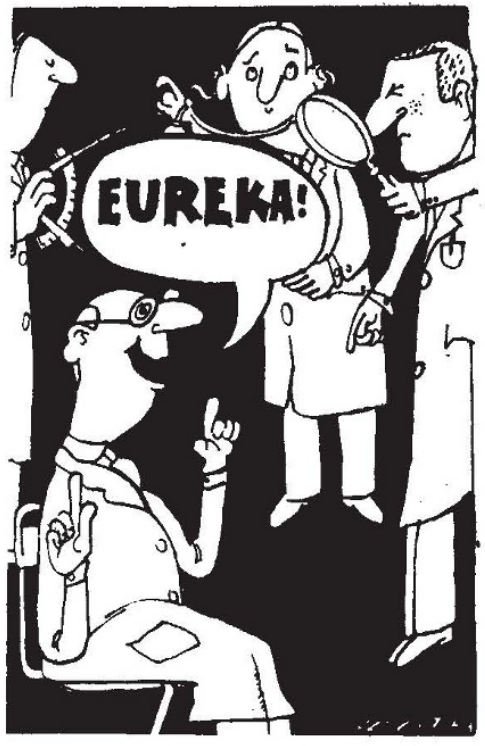

emerged about the conditions under which the creative process operates.

There are certain ground rules. One should not, for example, entertain any hypothesis unless it is one which "can be falsified even by an imaginary experiment". One needs to have "technical courage"-never be frightened of breaking a rule or switching to a new technique. Orthodoxy, says one speaker, is the enemy of creativity. One has to have the "capacity to pay attention to oddities"; a flair for elegance of thought, a sense of symmetry; something the symposium summed up as "good taste".

There are, too, certain environmental prerequisites. "You cannot be creative", says Eigen, "until you have new experiences". Eccles is even more specific. The experiences have got to be challenging: "Problems with ideas that are in conflict are an important challenge. Conflict is one of the most essential conditions". There is agreement about the necessity for an incubation periodfamiliar to those engaged on even the most modest kinds of creative workwhen the ideas are put out of mind for a time and (sometimes) become illuminated in a fresh and exciting way when they are re-examined. 'Playing with ideas' is an important element in the creative process, and there is some interesting talk as to whether the scientist has something to learn from the way children and animals engage in play.

What is the neurological and anatomical basis for creative thought? Eccles gives a lucid summary of the intricate way in which intentions in the brain are translated into action by muscles. But since uncreative people and even higher animals have similarly intricate neurological 'outfits', this gives no clue to the physical basis of the creative process. Indeed, one of the refreshing impressions one gets from reading this record of the conversations is of the readiness of creative scientists to admit that in the study of human behaviour there is what Popper calls "Erdenrest", "a remainder or residue which is not rational". This is not to say that rational thought must not be pushed to the very limits of human capacity; but it does mean that one must not exclude the possibility that some phenomena lie beyond rational thought, and will remain out of reach whatever advances science makes. Perhaps a better way to put this would be to say that if some human achievements are explained rationally, the achievements themselves vanish. Einstein is reported to have made a remark which illustrates this. Asked whether everything could ultimately be expressed in scientific terms he replied: "Yes, that is conceivable, but it would make no sense. It would be as if one were to reproduce Beethoven's Ninth Symphony in the form of an air pressure curve".

These conversations will not serve as much of a guide to aspirants hoping to acquire creativity. But they will help the ordinary mortal to appreciate more fully how the creative process works in those rare persons lucky enough to have the capacity for it. 